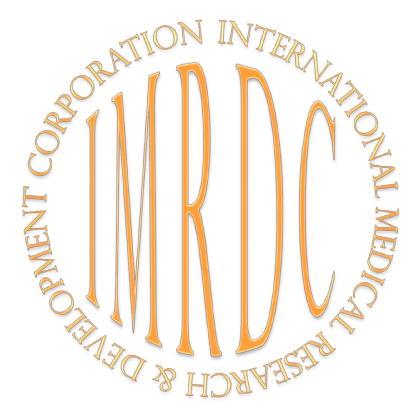

\title{
Cigarette Smoking and Components of the Metabolic Syndrome in the Indigenous Population of the Arctic Territory of Yakutia
}

\author{
Sargylana I. Sofronova, PhD*; Maria P. Kirillina, PhD; Vyacheslav M. Nikolaev, PhD; \\ Irina V. Kononova; PhD; Anna N. Romanova, $\mathrm{PhD}, \mathrm{ScD}$ \\ Yakut Science Center of Complex Medical Problems \\ Yakutsk, the Republic of Sakha (Yakutia), Russia
}

\begin{abstract}
The aim of this research was to study the influence of smoking on components of the metabolic syndrome and their relationship in the indigenous population of the Arctic territory of Yakutia.

Methods and Results: The material for the study was collected under expeditionary conditions in the Arctic territory of Yakutia in places of compact residence of indigenous peoples. Using the continuous method, we examined 348 subjects ( 225 women and $123 \mathrm{men})$. The average age of the respondents was $48.16 \pm 0.52$ years $(49.71 \pm 0.63$ years for women and $44.98 \pm 0.91$ years for men). The research program included the following sections: a questionnaire for objective assessment of state; anthropometric examination; assessment of blood pressure (BP); determination of insulin and fasting glucose. In the survey, only those who smoked at least 1 cigarette per day during the last 12 months were considered smokers. The obtained results indicate that the indigenous population of the northern territory of Yakutia has a high frequency of risk factors for the development of cardiovascular pathology, such as overweight, obesity, and smoking. Overweight is equally common in both men and women; obesity is almost 2.5 times more common in women. An increase in body weight and systolic BP is not associated with smoking; however, the simultaneous combination of all these factors can affect the risk of cardiovascular incidents. A negative relationship between body mass indexand smoking was found. An increased index of insulin resistance is associated with the simultaneous spread of obesity among nonsmokers. The same association of glucose level with BP was obtained in both smokers and nonsmokers.

Conclusion: Metabolic disorders in the indigenous population of the northern territory of Yakutia are caused by a change in the traditional way of life and nutrition, with a decrease in physical activity and a lack of adherence to a healthy lifestyle. (International Journal of Biomedicine. 2020;10(4):467-471.)
\end{abstract}

Key Words: smoking $\bullet$ overweight $\bullet$ obesity $\bullet$ insulin $\bullet$ glucose $\bullet$ systolic blood pressure $\bullet$ indigenous population $\bullet$ Yakutia

\section{Introduction}

The prevalence of overweight and obesity is a global epidemic affecting both developed and developing countries. ${ }^{(1-3)}$ Numerous researchers have demonstrated that there is a relationship between obesity and insulin resistance. Obesity is generally thought to lead to hyperinsulinemia based on pathophysiological and metabolic mechanisms. Hyperinsulinemia, in turn, leads to the development of the metabolic syndrome and type 2 diabetes mellitus.

*Corresponding author: Sargylana I. Sofronova, PhD. Yakut Science Center of Complex Medical Problems. Yakutsk, the Republic of Sakha (Yakutia),Russia.E-mail: sara2208@mail.ru
The connection between insulin resistance and the risk of developing cardiovascular pathology has been established in many studies. ${ }^{(4-10)}$

It is generally recognized that tobacco smoking is one of the negative factors affecting the human body. ${ }^{(11,12)}$ According to the WHO, more than a billion people smoke, with a steady increase every year. ${ }^{(13)}$ Russia is one of the top countries with a high prevalence of tobacco smoking. ${ }^{(14)}$ Scientists have received conflicting results on the effect of smoking on body mass index (BMI). For example, scientists have found that nicotine, acting on the levels of various neurotransmitters, such as catecholamines, dopamine, and serotonin, suppresses appetite and, therefore, reduces food intake, which results in a lower BMI. ${ }^{(15,16)} \mathrm{A}$ meta-analysis of prospective cohort studies in China, Singapore, and the United States showed 
that smokers with type 2 diabetes mellitus had an increased relative risk of cardiovascular complications and death. ${ }^{(17)}$ The relationship between BMI and insulin levels under the direct or indirect influence of tobacco smoking is currently widely discussed in the scientific community. ${ }^{(18,19)}$ Previously, results were published on the high prevalence of overweight and obesity among the indigenous peoples of the northern territory of Yakutia. ${ }^{(2)}$ Given the change in the traditional lifestyle and nutrition, the study of the relationship between smoking, obesity, and insulin levels in this population remains relevant and poorly understood.

The aim of this research was to study the influence of smoking on components of the metabolic syndrome and their relationship in the indigenous population of the Arctic territory of Yakutia.

\section{Materials and Methods}

The material for the study was collected under expeditionary conditions in the Arctic territory of Yakutia in places of compact residence of indigenous peoples (Nizhnekolymsky District, Verkhnekolymsky District, Tomponsky District). Using the continuous method, we examined 348 subjects (225 women and 123 men). Patient sample consisted of an adult population aged from 20 years to 70 years. The response rate was $70 \%$. Average age of the respondents was $48.16 \pm 0.52$ years $(49.71 \pm 0.63$ years for women and $44.98 \pm 0.91$ years for men).

Inclusion criteria: representatives of indigenous peoples of Yakutia (the Yakuts, the Evens, the Chukchi, the Yukagir). Exclusion criteria: representatives of non-indigenous nationality and the Yakuts. The sample was formed according to the administrative lists of employees of the settlements. The response was $76 \%$.

The research program included the following sections: a questionnaire for objective assessment of state; informed consent of the respondent to conduct research and donate blood; anthropometric examination; and blood sampling from the cubital vein in the morning on an empty stomach, with 12 hour abstinence from food. After centrifugation, blood serum was stored in a freezer $\left(-70^{\circ} \mathrm{C}\right)$ until analysis. In the survey, only those who smoked at least 1 cigarette per day during the last 12 months were considered smokers.

Overweight was considered to be a BMI $\geq 25 \mathrm{and}<30 \mathrm{~kg} / \mathrm{m}^{2}$, obesity was determined at a BMI of $\geq 30 \mathrm{~kg} / \mathrm{m}^{2}$.

Laboratory methods included the determination of insulin and fasting glucose. The generally accepted HOMA-IR index was used to calculate insulin resistance: ${ }^{(21,22)}$ (Fasting blood insulin in $\mathrm{mIU} / \mathrm{mL} \times$ Fasting blood glucose in $\mathrm{mmol} / \mathrm{L}) / 22.5$. An index value exceeding 2.7 is considered insulin resistance.

Blood pressure (BP) was measured twice with an OMRON M2 Basic automatic tonometer, with subjects in a sitting position. Average BP was calculated with a margin of permissible measurement error of $\pm 3 \mathrm{mmHg}$, according to the instructions for the correct measurement of BP outlined in the European clinical guidelines for the diagnosis and treatment of hypertension. The diagnosis of hypertension was based on 2017 ACC/AHA Guideline for or the Prevention, Detection, Evaluation, and
Management of High Blood Pressure in Adults. ${ }^{(23)}$

The study was approved by the Ethics Committee of the Yakut Science Center of Complex Medical Problems. Written informed consent was obtained from each patient.

Statistical analysis was performed using IBM SPSS Statistics for Windows, Version 19.0 (Armonk, NY: IBM Corp.). The normality of distribution of continuous variables was tested by the Kolmogorov-Smirnov test with the Lilliefors correction and Shapiro-Wilk test. Baseline characteristics were summarized as frequencies and percentages for categorical variables and as mean $\pm \mathrm{SEM}$ for continuous variables. For data with normal distribution, inter-group comparisons were performed using Student's t-test. Differences of continuous variables departing from the normal distribution, even after transformation, were tested by the Mann-Whitney U-test. The frequencies of categorical variables were compared using the Chi-square test. Spearman's rank correlation coefficient was calculated to measure the strength and direction of the relationship between two variables. A probability value of $P<0.05$ was considered statistically significant.

\section{Results and Discussion}

In the general population, almost half of the respondents $(45.7 \%)$ were found to smoke; men had the largest percentage of smokers - $59.3 \%$, women $-38.2 \%$.

The average BMI was significantly higher in women than in men $\left(28.73 \pm 0.42 \mathrm{~kg} / \mathrm{m}^{2}\right.$ and $25.51 \pm 0.36 \mathrm{~kg} / \mathrm{m}^{2}$, respectively, $P<0.001$ ). In the general population, $35.9 \%$ of the respondents were overweight, and $31.9 \%$ were obese; $36 \%$ of women were overweight, $39.6 \%$ were obese. In men, $35.8 \%$ and $17.9 \%$, respectively. Thus, an equally high incidence of overweight was found in both men and women. Obesity is most common among the female population. The high incidence of overweight, BMI and obesity is due to changes in lifestyle and low physical activity, especially among women.

We conducted a study on the relationship between smoking and BMI. In nonsmokers, BMI was statistically significantly higher than in smokers $\left(28.93 \pm 0.44 \mathrm{~kg} / \mathrm{m}^{2}\right.$ and $26.01 \pm 0.39 \mathrm{~kg} / \mathrm{m}^{2}$, respectively, $P<0.001$ ). In nonsmoking men, as well as in women, the mean BMI was significantly higher than in nonsmokers (men: $27.20 \pm 0.58 \mathrm{~kg} / \mathrm{m}^{2}$ and $24.36 \pm 0.41 \mathrm{~kg} / \mathrm{m}^{2}, P<0.001$; women: $29.55 \pm 0.55 \mathrm{~kg} / \mathrm{m}^{2}$ and $\left.27.42 \pm 0.60 \mathrm{~kg} / \mathrm{m}^{2}, P=0.013\right)$. A negative relationship between BMI and smoking has been confirmed in many studies; ${ }^{(15,16)}$ nevertheless, it has been shown that smoking is an independent risk factor for the development of cardiovascular diseases, including stroke and coronary heart disease..$^{(12,24-26)}$

Table 1 presents a comparative analysis of overweight and obesity in the general population, depending on gender and on the status of smoking. The frequency of overweight in the general population of smokers was higher than in nonsmokers due to the higher rate of obesity among female smokers; however, the differences are statistically insignificant. With regard to obesity, all respondents had a significantly higher incidence of obesity in nonsmokers than in smokers. In our study, smoking did not affect the development of constitutional obesity, which is confirmed by the studies 
of several researchers on the effect of nicotine on weight loss through an increase in various neurotransmitters. ${ }^{(15,16)}$

Table 1.

Frequency of overweight and obesity by BMI depending on status of smoking (\%)

\begin{tabular}{|l|l|c|c|c|c|}
\hline \multicolumn{2}{|c|}{} & Overweight & P-value & Obesity & P-value \\
\hline \multirow{3}{*}{ Total } & smokers & 37.7 & \multirow{2}{*}{0.587} & 20.8 & \multirow{2}{*}{0.001} \\
\cline { 2 - 3 } & nonsmokers & 34.4 & & 41.3 & \\
\hline \multirow{2}{*}{ Men } & smokers & 32.9 & \multirow{2}{*}{0.412} & 9.6 & \multirow{2}{*}{0.042} \\
\cline { 2 - 3 } & nonsmokers & 40.0 & & 30.0 & \\
\hline \multirow{2}{*}{ Women } & smokers & 41.9 & \multirow{2}{*}{0.122} & 30.2 & \multirow{2}{*}{0.039} \\
\cline { 2 - 3 } & nonsmokers & 32.4 & & 45.3 & \\
\hline
\end{tabular}

Comparing the systolic BP (SBP) level among the respondents, depending on their smoking status, the following results were obtained. In smokers, the average SBP was significantly lower than in nonsmokers $(134.84 \pm 1.85 \mathrm{mmHg}$ and $147.83 \pm 1.98 \mathrm{mmHg}$, respectively, $P<0.001$ ), while the average SBP in nonsmokers was higher than normal. There was also a negative correlation between the number of smoked cigarettes and the level of SBP $(\mathrm{r}=-0.226, P<0.001)$; the statistically significant correlation was obtained in women $(\mathrm{r}=-0.220, P=0.001)$ than in men $(\mathrm{r}=-0.147, P=0.104)$. Accordingly, $64.2 \%$ of nonsmoking respondents had a significantly increased BP, compared with smokers, whose BP increased in $35.8 \%$ of cases $(P<0.001)$. Thus, we obtained results in which smoking is not associated with an increase in BP, possibly due to its indirect effect on BMI reduction. Results obtained by Li et al. ${ }^{(27)}$ also revealed that the adjusted BP was lower in current smokers versus nonsmokers and former smokers. Nevertheless, according to previous research, the combination of these two risk factors affects the mortality rate from cardiovascular complications. ${ }^{(12,17,24-26,28,29)}$

Due to conflicting research data on the effect of smoking on the level of insulin secretion, we carried out a comparative analysis of the average values of insulin and the HOMA-IR index in respondents, depending on their relationship with smoking. The average insulin concentration did not exceed the reference values in smokers; it was $7.19 \pm 1.23 \mathrm{IU} / \mathrm{ml}$, which was significantly lower than in nonsmokers $(12.74 \pm 2.35$ $\mathrm{IU} / \mathrm{ml})(P=0.035)$. By gender, only men had significant differences in mean insulin concentration $(4.91 \pm 0.75 \mathrm{IU} / \mathrm{ml}$ in smokers and $8.42 \pm 1.76 \mathrm{IU} / \mathrm{ml}$ in non-smokers, $P=0.034$ ). There were no significant differences in women. We also determined the average values of the HOMA-IR index, which were $1.48 \pm 0.24$ in smokers and $2.77 \pm 0.46$ in nonsmoking respondents $(P=0.014)$. In nonsmokers, these indicators were higher than the reference values. Thus, our study shows that smoking suppresses insulin secretion, which may affect the development of type 2 diabetes. Similar results were obtained in the studies of certain foreign researchers. ${ }^{(18,19)}$ The increased HOMA-IR index in nonsmoking respondents, which characterizes insulin resistance, is most likely associated with the prevalence of obesity among them.
When comparing the relationship between the number of smoked cigarettes and BMI, we obtained a statistically significant negative correlation $(\mathrm{r}=-0.318, P<0.001)$. This correlation was more clearly observed in men $(\mathrm{r}=-0.423$, $P<0.001)$ than in women $(\mathrm{r}=-0.134, P=0.088)$. With insulin, a weak inverse relationship was obtained with the number of cigarettes smoked $(\mathrm{r}=-0.140, P=0.029)$. Separately, in men and women, there was no clear relationship (men: $\mathrm{r}=-$ $0.163, P=0.153$; women: $\mathrm{r}=-0.140, P=0.029$ ). We did not find any particular relationship between the number of cigarettes smoked and the glucose level $(\mathrm{r}=-0.045, P=0.489)$. Separately, in men and women, there was no correlation either. The obtained result does not reflect the influence of one of the risk factors on the development of atherosclerosis and type 2 diabetes mellitus, since we have not determined the duration of smoking. Thus, the number of cigarettes smoked was not associated with BMI and insulin levels.

We analyzed the association of insulin, glucose, SBP and BMI parameters under the direct influence of smoking, and we studied the relationship between insulin and the level of SBP in the general population. There was a weak positive correlation between insulin levels and SBP $(\mathrm{r}=0.239$, $P=0.003$ ), which is confirmed by studies abroad. ${ }^{(6,8,31)}$ Analysis of the effect of smoking on the relationship between insulin and SBP showed that nonsmokers had a significant but weak correlation $(\mathrm{r}=0.197, P=0.034)$, in contrast to smokers $(\mathrm{r}=0.116, P=0.198)$.

A study of the relationship between insulin levels and BMI showed that there was a positive correlation between these indicators $(\mathrm{r}=0.283, P<0.001)$. Depending on the smoker's adherence to smoking, the level of insulin was significantly correlated with BMI, equal to the correlation for nonsmokers $(\mathrm{r}=0.283$ and $\mathrm{r}=0.223$, respectively, $P<0.05$ in both cases). As for the relationship between glucose level and BMI, a weak correlation was obtained in nonsmokers ( $\mathrm{r}=0.287, P=0.002)$, but not in smokers $(\mathrm{r}=0.031, P=0.731)$. Glucose was also associated with SBP in both smokers $(\mathrm{r}=0.183, P=0.021)$ and nonsmokers ( $\mathrm{r}=0.420, P<0.001)$. Thus, an association between the insulin level and BMI was obtained, including in smokers, which is confirmed by a number of studies abroad. ${ }^{(4,8,18)}$

In summary, the indigenous population of the northern territory of Yakutia has a high frequency of risk factors for the development of cardiovascular pathology, such as overweight, obesity, and smoking. Overweight is equally common in both men and women; obesity is almost 2.5 times more common in women. An increase in body weight and SBP is not associated with smoking; however, the simultaneous combination of all these factors can affect the risk of cardiovascular incidents. We have confirmed the data of foreign scientists on the suppression of the level of insulin secretion under the influence of nicotine. An increased index of insulin resistance is associated with the simultaneous spread of obesity among nonsmokers. The same association of glucose level with BP was obtained in both smokers and nonsmokers. Metabolic disorders in the indigenous population of the northern territory of Yakutia are caused by a change in the traditional way of life and nutrition, with a decrease in physical activity and a lack of adherence to a healthy lifestyle. By addressing modifiable 
risk factors, including overweight, obesity, and smoking, it is possible to prevent morbidity and premature mortality from cardiovascular disease.

\section{Competing Interests} interests.

The authors declare that they have no competing

\section{References}

1. Gutiérrez-Fisac JL, Guallar-Castillón P, León-Muñoz LM, Graciani A, Banegas JR, Rodríguez-Artalejo F. Prevalence of general and abdominal obesity in the adult population of Spain, 2008-2010: the ENRICA study. Obes Rev. 2012 Apr;13(4):388-92. doi: 10.1111/j.1467-789X.2011.00964.x.

2. Popkin BM, Adair LS, Ng SW. Global nutrition transition and the pandemic of obesity in developing countries. Nutr Rev. 2012 Jan;70(1):3-21. doi: 10.1111/j.1753-4887.2011.00456.x. 3. Stevens GA, Singh GM, Lu Y, Danaei G, Lin JK, Finucane MM, Bahalim AN, McIntire RK, Gutierrez HR, Cowan M, Paciorek CJ, Farzadfar F, Riley L, Ezzati M; Global Burden of Metabolic Risk Factors of Chronic Diseases Collaborating Group (Body Mass Index). National, regional, and global trends in adult overweight and obesity prevalences. Popul Health Metr. 2012 Nov 20;10(1):22. doi: 10.1186/1478-795410-22.

4. Gustafson B, Hedjazifar S, Gogg S, Hammarstedt A, Smith U. Insulin resistance and impaired adipogenesis. Trends Endocrinol Metab. 2015 Apr;26(4):193-200. doi: 10.1016/j. tem.2015.01.006.

5. Beverly JK, Budoff MJ. Atherosclerosis: Pathophysiology of insulin resistance, hyperglycemia, hyperlipidemia, and inflammation. J Diabetes. 2020 Feb;12(2):102-104. doi: 10.1111/1753-0407.12970.

6. Bloomgarden ZT. Insulin resistance, dyslipidemia, and cardiovascular disease. Diabetes Care. 2007 Aug;30(8):216470. doi: $10.2337 / \mathrm{dc} 07-\mathrm{zb} 08$.

7. Eddy D, Schlessinger L, Kahn R, Peskin B, Schiebinger R. Relationship of insulin resistance and related metabolic variables to coronary artery disease: a mathematical analysis. Diabetes Care. 2009 Feb;32(2):361-6. doi: 10.2337/dc080854 .

8. Laakso M, Kuusisto J, Stančáková A, Kuulasmaa T, Pajukanta P, Lusis AJ, Collins FS, Mohlke KL, Boehnke M. The Metabolic Syndrome in Men study: a resource for studies of metabolic and cardiovascular diseases. J Lipid Res. 2017 Mar;58(3):481-493. doi: 10.1194/jlr.O072629.

9. Reaven G. Insulin resistance and coronary heart disease in nondiabetic individuals. Arterioscler Thromb Vasc Biol. 2012 Aug;32(8):1754-9. doi: 10.1161/ATVBAHA.111.241885.

10. Hirai FE, Moss SE, Klein BE, Klein R. Relationship of glycemic control, exogenous insulin, and C-peptide levels to ischemic heart disease mortality over a 16 -year period in people with older-onset diabetes: the Wisconsin Epidemiologic Study of Diabetic Retinopathy (WESDR). Diabetes Care. 2008 Mar;31(3):493-7. doi: 10.2337/dc07-1161.

11. Howard G, Wagenknecht LE, Burke GL, Diez-Roux A, Evans GW, McGovern P, Nieto FJ, Tell GS. Cigarette smoking and progression of atherosclerosis: The Atherosclerosis Risk in Communities (ARIC) Study. JAMA. 1998 Jan 14;279(2):11924. doi: 10.1001/jama.279.2.119.
12. Pujades-Rodriguez M, George J, Shah AD, Rapsomaniki E, Denaxas S, West R, Smeeth L, Timmis A, Hemingway H. Heterogeneous associations between smoking and a wide range of initial presentations of cardiovascular disease in 1937360 people in England: lifetime risks and implications for risk prediction. Int J Epidemiol. 2015 Feb;44(1):129-41. doi: $10.1093 / \mathrm{ije} /$ dyu 218.

13. WHO Report on the Global Tobacco Epidemic; 2013. Available at https://www.who.int/tobacco/global report/2013/en/

14. WHO global report on trends in prevalence of tobacco smoking 2000-2025 - Second edition. Available at: https:// www.who.int/tobacco/publications/surveillance/trendstobacco-smoking-second-edition/en/.

15. Audrain-McGovern J, Benowitz NL. Cigarette smoking, nicotine, and body weight. Clin Pharmacol Ther. 2011 Jul;90(1):164-8. doi: 10.1038/clpt.2011.105.

16. Benowitz NL. Nicotine addiction. N Engl J Med. 2010 Jun 17;362(24):2295-303. doi: 10.1056/NEJMra0809890.

17. Pan A, Wang Y, Talaei M, Hu FB. Relation of Smoking With Total Mortality and Cardiovascular Events Among Patients With Diabetes Mellitus: A Meta-Analysis and Systematic Review. Circulation. 2015 Nov 10;132(19):1795804. doi: 10.1161/CIRCULATIONAHA.115.017926.

18. Li Y, Zhang T, Han T, Li S, Bazzano L, He J, Chen W. Impact of cigarette smoking on the relationship between body mass index and insulin: Longitudinal observation from the Bogalusa Heart Study. Diabetes Obes Metab. 2018 Jul;20(7):1578-1584. doi: 10.1111/dom.13259.

19. Morimoto A, Tatsumi Y, Deura K, Mizuno S, Ohno Y, Watanabe S. Impact of cigarette smoking on impaired insulin secretion and insulin resistance in Japanese men: The Saku Study. J Diabetes Investig. 2013 May 6;4(3):274-80. doi: 10.1111/jdi.12019.

20. Sofronova SI, Romanova AN, Kirillina MP, Nikolaev VM. [Ethnicity-dependent evaluation of excessive body mass and obesity in the native population of northern Yakutia]. Yakut Medical Journal. 2019;(2):76-78. doi: 10.25789/ YMJ.2019.66.23. [Article in Russian].

21. Matthews DR, Hosker JP, Rudenski AS, Naylor BA, Treacher DF, Turner RC. Homeostasis model assessment: insulin resistance and beta-cell function from fasting plasma glucose and insulin concentrations in man. Diabetologia. 1985 Jul;28(7):412-9. doi: 10.1007/BF00280883.

22. Wallace TM, Levy JC, Matthews DR. Use and abuse of HOMA modeling. Diabetes Care. 2004 Jun;27(6):1487-95. doi: $10.2337 /$ diacare.27.6.1487.

23. Whelton PK, Carey RM, Aronow WS, Casey DE Jr, Collins KJ, Dennison Himmelfarb C, DePalma SM, Gidding S, Jamerson KA, Jones DW, MacLaughlin EJ, Muntner P, Ovbiagele B, Smith SC Jr, Spencer CC, Stafford RS, Taler SJ, Thomas RJ, Williams KA Sr, Williamson JD, Wright JT Jr. 2017 ACC/AHA/AAPA/ABC/ACPM/AGS/APhA/ASH/ ASPC/NMA/PCNA Guideline for the Prevention, Detection, Evaluation, and Management of High Blood Pressure in Adults: A Report of the American College of Cardiology/American Heart Association Task Force on Clinical Practice Guidelines. J Am Coll Cardiol. 2018 May 15;71(19):e127-e248. doi: 10.1016/j.jacc.2017.11.006.

24. Dolgalev IV, Brazovskaya NG, Ivanova AYu, Shipkhineeva AYu, Bogaychuk PM. [Influence of arterial hypertension, smoking, and their combination on mortality (according to the results of a 27-year cohort prospective study 
of the unorganized population of Tomsk)]. Russian Journal of Cardiology. 2019;(1):32-37. doi: 10.15829/1560-4071-20191-32-37. [Article in Russian].

25. Maksimov SA, Skripchenko AE, Indukaeva EV, Mulerova TA, Danilchenko YV, Tabakaev MV, Artamonova GV. [Relationships between smoking, coronary artery disease and cardiovascular risk factors (ESSE-RF in the Kemerovo region)]. Complex Issues of Cardiovascular Diseases. 2017;6(4):21-26. doi: 10.17802/2306-1278-2017-6-4-21-26. [Article in Russian].

26. LeoneA. Smoking and hypertension: independent or additive effects to determining vascular damage? Curr Vasc Pharmacol. 2011 Sep;9(5):585-93. doi: 10.2174/157016111796642706.

27. Li G, Wang H, Wang K, Wang W, Dong F, Qian Y, Gong H, Hui C, Xu G, Li Y, Pan L, Zhang B, Shan G. The association between smoking and blood pressure in men: a cross-sectional study. BMC Public Health. 2017 Oct 10;17(1):797. doi: 10.1186/s12889-017-4802-x.

28. Carter BD, Abnet CC, Feskanich D, Freedman ND, Hartge
P, Lewis CE, Ockene JK, Prentice RL, Speizer FE, Thun MJ, Jacobs EJ. Smoking and mortality--beyond established causes. N Engl J Med. 2015 Feb 12;372(7):631-40. doi: 10.1056/ NEJMsa1407211.

29. Pannier B, Thomas F, Hanon O, Czernichow S, Lemogne C, Simon T, Simon JM, Danchin N. Individual 6-year systolic blood pressure change and impact on cardiovascular mortality in a French general population. J Hum Hypertens. 2016 Jan;30(1):18-23. doi: 10.1038/jhh.2015.44.

30. Pan A, Wang Y, Talaei M, Hu FB. Relation of Smoking With Total Mortality and Cardiovascular Events Among Patients With Diabetes Mellitus: A Meta-Analysis and Systematic Review. Circulation. 2015 Nov 10;132(19):1795804. doi: 10.1161/CIRCULATIONAHA.115.017926.

31. Purohit P, Mathur R. Hypertension association with serum lipoproteins, insulin, insulin resistance and C-Peptide: unexplored forte of cardiovascular risk in hypothyroidism. N Am J Med Sci. 2013 Mar;5(3):195-201. doi: 10.4103/19472714.109187. 